\title{
Exploring Opportunities for Inclusive Education for Children with Intellectual and Developmental Disabilities in Ghana
}

\author{
De-Lawrence Lamptey \\ School of Rehabilitation Therapy \\ Queen's University, Kingston \\ Ontario, Canada
}

\begin{abstract}
This research seeks to identify challenges faced by children with intellectual and developmental disabilities to inclusive education in Ghana and provide some strategies on how to address these challenges. This research will be qualitative. Data will be gathered through interviews. The interviews will be conducted with fifteen parents/caregivers of children with intellectual and developmental disabilities, ten mainstream school teachers, ten special school teachers and ten school heads. The method of constant comparison (coding, categories and concepts) will be used to analyze the data. It is expected that this research will identify major challenges faced by children with intellectual and developmental disabilities to inclusive education in Ghana and provide some strategies that can be used to promote inclusive education for these children in the Ghanaian context.
\end{abstract}

\section{Introduction}

In 1990, a world education conference was held in Jomtein to discuss ways of meeting the educational needs of every child in the world among the State Parties of the United Nations. The Education for All (EFA) agenda was adopted at that conference to meet the learning needs of all children, including those with disabilities. Another world conference was held in 2000 at Dakar to assess progress made on the EFA a decade after its declaration and to make further recommendations on advancing the EFA goal [1] [2]. At both conferences, the need for countries to provide inclusive education for all children and to put in place education systems that meet the educational needs of children with disabilities in mainstream schools in the communities where they live was emphasized [1] [2]. Ghana was present at both conferences and as a result, the country has taken a policy initiative to achieve the EFA goal by 2015 [3] [4]. The purpose of this extended paper is to propose a study to investigate the challenges that children with intellectual and developmental disabilities in Ghana encounter with regard to accessing inclusive education. The study further seeks to involve parents/caregivers, mainstream teachers, special school teachers and school heads in formulating strategies that can be helpful to promote inclusive education for children with intellectual and developmental disabilities in Ghana. The literature indicates that in order for children with intellectual and developmental disabilities to optimally benefit from inclusive education, it is necessary to support and empower their parents/caregivers and school teachers/educators enable them to meet the teaching and learning needs of such children in inclusive settings [5] [6].

In many cultures of Ghana, disability is believed to be caused through such means as demon possession, witchcraft, curses and punishment from a deity [7]. This situation has led to stigmatization and discrimination of people with disabilities in the Ghanaian society [7]. Evidence indicates that children with disabilities are murdered, hidden from public view and excluded from mainstream opportunities for their development in Ghana [8] [9]. Avoke purports that though these attitudes are expressed towards all people with disabilities, those with intellectual disabilities are the most affected [8]. Inclusive education has been recognized by the international community as the most effective way to fight these discriminatory attitudes towards persons with disabilities and create welcoming societies for all people, regardless of their abilities or disabilities [1] [2]. Though Ghana has a policy to provide inclusive education for all, according to Botts and Owusu, children with intellectual and developmental disabilities are excluded from mainstream education systems in the country [3] [4] [10]. Education for children with disabilities is considered a human right issue globally, and every child with disabilities, including those with intellectual and developmental disabilities, has a fundamental right to benefit from mainstream education systems in his/her community and to receive the necessary support to succeed in such systems [11].

Inclusive education entails identifying and removing barriers, and providing reasonable 
accommodation to enable every child to participate and achieve within mainstream educational settings, taking into account his or her individual abilities [6]. There is no conclusive definition of inclusive education in the literature. Nonetheless, inclusion can be conceptualized into the following themes: access, equity and support [12]. Access is the extent to which environmental barriers to educational opportunities are addressed to promote the inclusion of students with disabilities in regular/mainstream schools. Access to learning environments, educational routines and curriculum needs to be provided for children with disabilities at regular/mainstream schools to enable them to enroll in such schools [13]. Equity refers to fairness in available opportunities at school for all regardless of abilities/disabilities. To provide equity, school programs need to be tailored toward the unique learning abilities of every student (including those with disabilities) in the classroom and educational assessments at schools also need to be based on individual progress rather than purely academic performance [12]. Support, on the other hand, refers to resources and services that are made available to enable students with disabilities fully make good use of and benefit from mainstream education systems in their communities. Some children with disabilities, especially those with intellectual and developmental disabilities, require additional resources such as adaptive teaching and learning aids, and support services like occupational therapy and physical therapy to make it possible for them to benefit from teaching and learning (or other school activities such as sports) at mainstream schools [13].

Studies on inclusive education in Ghana have focused on assessing teachers' attitudes and knowledge about inclusive educational practices [14] [15] [16]. Others have also focused on placement for children with visual impairments in regular education settings [17]. However, as mentioned before, the literature on inclusion indicates that in order for children with disabilities to optimally benefit from inclusive education, it is necessary to support their parents/caregivers and school teachers/educators to meet their educational needs in inclusive settings [5] [6]. According to the WHO and World Bank, across the world, children with physical disability have higher school enrollment rates than children with intellectual and developmental disabilities, hence, the study will focus on children with intellectual and developmental disabilities in Ghana [4]. The study will also be limited to basic education because the Constitution of the Republic of Ghana, 1992 states that basic education should be free, compulsory and accessible to all children [18]. The research questions for the study are as follows:
(1) What challenges do children with intellectual and developmental disabilities face in accessing inclusive education in Ghana? (1(a) what are the challenges parents/caregivers face in accessing mainstream education for their children with intellectual and developmental disabilities, and 1(b) what challenges do or will teachers and school heads face in meeting the educational needs of children with intellectual and developmental disabilities in mainstream schools?)

(2) What strategies do parents/caregivers, teachers and schools heads want to be employed to improve upon their abilities to provide inclusive education for children with intellectual and developmental disabilities in Ghana?

The first research question will be conceptualized using these themes of inclusion - access, equity and support [12]. The 4-I model of Appreciative Inquiry by Preskill and Catsambas will be used to conceptualize the second research question [19]. This model has four phases, namely: (1) Inquire, (2) Imagine, (3) Innovate, and (4) Implement. The first phase, Inquire, requires individuals to tell a story about when things were successful for them in their situations. The second phase, Imagine, allows individuals to develop a vision for the future of their situations. The third phase, Innovate, allows individuals to think about how change can occur and acknowledge what is required to implement the change they want. Finally, the fourth phase, Implement, asks individuals to act on and make changes based on the recommendations they made in the first three phases concerning their situations [19].

\section{Methodology}

The site for data collection is Accra, Ghana. Accra is the capital of Ghana and as such the city has a high volume of schools for nondisabled children and a number of special schools (both public and private). The city, thus, offers a large pool from which to draw participants for the study.

Qualitative research approaches will guide the process of data collection and analysis in this study. These research approaches allow researchers to explore meanings individuals attach to any phenomenon under investigation and they also allow for the mutual construction of knowledge by both researchers and study participants [20]. These approaches best suit the purpose of the study as they will be useful to allow the researcher to explore the challenges that children with intellectual and developmental disabilities encounter in accessing inclusive education from the perspective of their 
parents/caregivers, teachers and school heads. Again, they will allow the researcher to explore strategies that can be used to improve inclusive education for these children from the perspectives of their parents/caregivers, teachers and school heads.

Since the essence of qualitative research is to provide in-depth exploration of the meaning individuals ascribe to the phenomenon under investigation, it is typical for such studies to have small sample sizes in order to make data collection and analysis more manageable [20]. The convenient sampling method will be used to select participants for this research. This type of sampling method allows researchers to conveniently include participants in a study based on their availability, suitability and willingness to participate [20]. The study participants will be made up of fifteen parents/caregivers of children with intellectual and developmental disabilities who fall within the age range for basic education in Ghana (6-15years), ten basic education teachers, ten school heads and ten special school teachers.

The main tools for data collection are semistructured interviews. The interviews will be structured around the themes of inclusion mentioned before - access, equity and support, and the 4-I model of Appreciative Inquiry [12] [19]. They will examine the participants' knowledge on challenges to inclusive education for children with intellectual and developmental disabilities as well as what can be done to promote inclusion for the children in Ghana. All questions for the interview will be piloted with a representative sample of the participants to verify their suitability for the study, and modified where necessary, before data collection. The interviews will be either face to face or telephone interviews and they will be recorded in audio format. Each interview is expected to last for about an hour and they will be conducted at a place where the participants finds most convenient.

The method of constant comparison will be used to analyze the data. This method of data analysis entails coding, categories and emerging themes [20]. Data analysis will begin by describing the interviews. The transcripts will be read thoroughly several times for summaries of similar responses and ideas (coding). This will be followed by grouping the summaries of similar responses and ideas under major/broad topics (categories). Finally, key concepts (emerging themes) that reflect the meaning the researcher attaches to the data and that are central to the purpose of the study will be identified from the categories and reported as the findings of this research.

Methods such as triangulation, reflexivity, audit trail, member checking and peer debriefing will be used to enhance qualitative rigor in the study [20]. For example, interviews conducted will be compared both within the various categories of participants and among them to check for similarities as well as differences in responses. Throughout the process of data collection and analysis, the researcher will keep a journal of his thoughts and assumptions in order to report how his interpretations of data has been shaped by his personal experience in the final report. The participants will be contacted for further clarification on certain portions of their respective interviews if need be during data analysis by email or by telephone. The researcher will note important quotes that support portions of the research findings and include them in the final report. Low inference descriptors will also be employed in the final report to preserve the original language used by participants during data collection as much as possible.

\section{Results}

It is expected that this study will identify major challenges faced by children with intellectual and developmental disabilities in Ghana face in accessing inclusive education. Additionally, it is expected that it will identify strategies that could be used to promote the inclusion of these children in the Ghanaian context from the perspectives of their parents/caregivers, mainstream teachers, special school teachers and school heads.

\section{Discussion}

The findings of this research can be used as a platform to advocate for and push forward the rights of children with intellectual and developmental disabilities to inclusive educational opportunities in Ghana. The findings can serve as a baseline for the formulation of strategies to promote their inclusion in mainstream schools in the Ghanaian context. By providing strategies on how to improve inclusive education for children with intellectual and developmental disabilities, this research can be a helpful resource to Ghana as the country works towards achieving the global Education for All (EFA) agenda. Teacher training institutions can also use the findings to enhance their curriculum to better prepare teacher-trainees to meet the educational needs of children with developmental and intellectual disabilities in mainstream schools. 


\section{References}

[1] United Nations Educational, Scientific and Cultural Organization, World Declaration on Education for All, UNESCO, Paris, 1990.

[2] United Nations Educational, Scientific and Cultural Organization, Education for All: Meeting our Collective Commitments. Notes on the Dakar Framework for Action, UNESCO, Paris, 2000.

[3] Republic of Ghana, Education strategic plan 20102020, Volume 1, Policies, Strategies, Delivery, Finance, Ministry of Education, Accra, 2010.

[4] World Health Organization (WHO) and World Bank, World Report on Disability, WHO and World Bank, Geneva, 2011.

[5] M. Alur, "Family Perspectives - Parents in partnership", in R. Rose (Ed), Confronting Obstacles to Inclusion - International Responses to Developing Inclusive Education, Routledge, Abingdon, 2010, pp. 8093.

[6] Hutchinson, N. L., and A. K. Martin, Inclusive Classrooms in Ontario Schools, Pearson Canada, Toronto, 2012.

[7] Mensah, O., J. Williams, R. Atta-Ankomah and M. Mjomba. Contextual Analysis of the Disability Situation in Ghana, JMK Research Consulting, Legon, Ghana, 2008.

[8] M. Avoke, "Models of Disability in the Labeling and Attitudinal Discourse in Ghana", Disability \& Society, 17(7), 2002, pp. 769-777.

[9] A. K. Kassah, L. L. Kassah and T. K. Agbota, "Abuse of Disabled Children in Ghana", Disability \& Society, 27(5), 2012, pp. 689-701.

[10] B. H. Botts, and N. A. Owusu, "The State of Inclusive Education in Ghana, West Africa", Preventing School Failure: Alternative Education for Children and Youth, 57(3), 2013, pp. 135-143.

[11] United Nations, Convention on the Rights of Persons with Disabilities, UN, New York, 2006.

[12] McColl, M. A, and L. Jongbloed, (Eds.), Disability and Social Policy in Canada, (2nd ed), Captus Press, Concord ON, 2006.

[13] Division for Early Childhood/National Association for the Education for Young Children, Early childhood inclusion: A joint position statement of the division for early childhood (DEC) and the national association for the education of young children (NAEYC), University of North Carolina, FPG Child Development Institute, Chapel Hill, 2009.
[14] P. Deku and F. R. Ackah, "Teachers Conceptualization of Inclusive Education in Ghana", Ife PsychologIA, 20(1), 2012, pp. 152-164.

[15] E. K. Gyimah, “Teachers' Use of Instructional Strategies in Primary Schools in Ghana: Implication to Inclusive Education", Education Research Journal, 1(3), 2011, pp. 46-52.

[16] E. K. Gyimah, D. Sugden, and S. Pearson, "Inclusion of Children with Special Educational Needs in Mainstream Schools in Ghana: Influence of Teachers' and Children's Characteristics", International Journal of Inclusive Education, 13(8), 2009, pp. 787-804.

[17] K. W. Ageke, "Impact of Segregation and Inclusive Education at the Basic Education Level on Children with Low Vision in Ghana", International Congress Series, 1282, 2005, pp. 775-779.

[18] Republic of Ghana, 1992 Constitution of the Republic of Ghana, Republic of Ghana, Accra, 1992.

[19] Preskill, H. S., and T. T. Catsambas, Reframing Evaluation through Appreciative Inquiry, Sage Publications, Thousand Oaks, California, 2006.

[20] Creswell, J. W., Research Design: Qualitative, quantitative, and Mixed Methods Approaches, Sage, Los Angeles, 2009. 